$\mathrm{V}_{\text {Zustöß } \beta \text {, ist so }}^{\text {ichts, werwartet }}$ wie das Alter.

Leo Trotzki, russischer Politiker

$K^{n}$ uchen gibt's nie allein. Sondern immer nur zusammen mit einem Vortrag.

Georg Schramm, deutscher Kabarettist

M it dem Alter ist das ganz einfach: Mans wird eben älter.

Mick Jagger, britischer Rocksänger

$Z_{\text {s heißt, das erste, was im Al- }}$ die Beine und die Augen. Das stimmt nicht. Das erste, was nicht mehr funktioniert, ist das rückwärts einparken.

Kurt Vonnegut, amerikanischer Schriftsteller

Tch habe das Glück gehabt, ein ereignisloses Leben zu führen.

Walter Helmut Fritz, deutscher Schriftsteller

W Ter die Altersheime kritisiert, sollte sich die Wohnungen der anderen Alten ansehen.

Gerhard Kocher, Schweizer Gesundheitsökonom

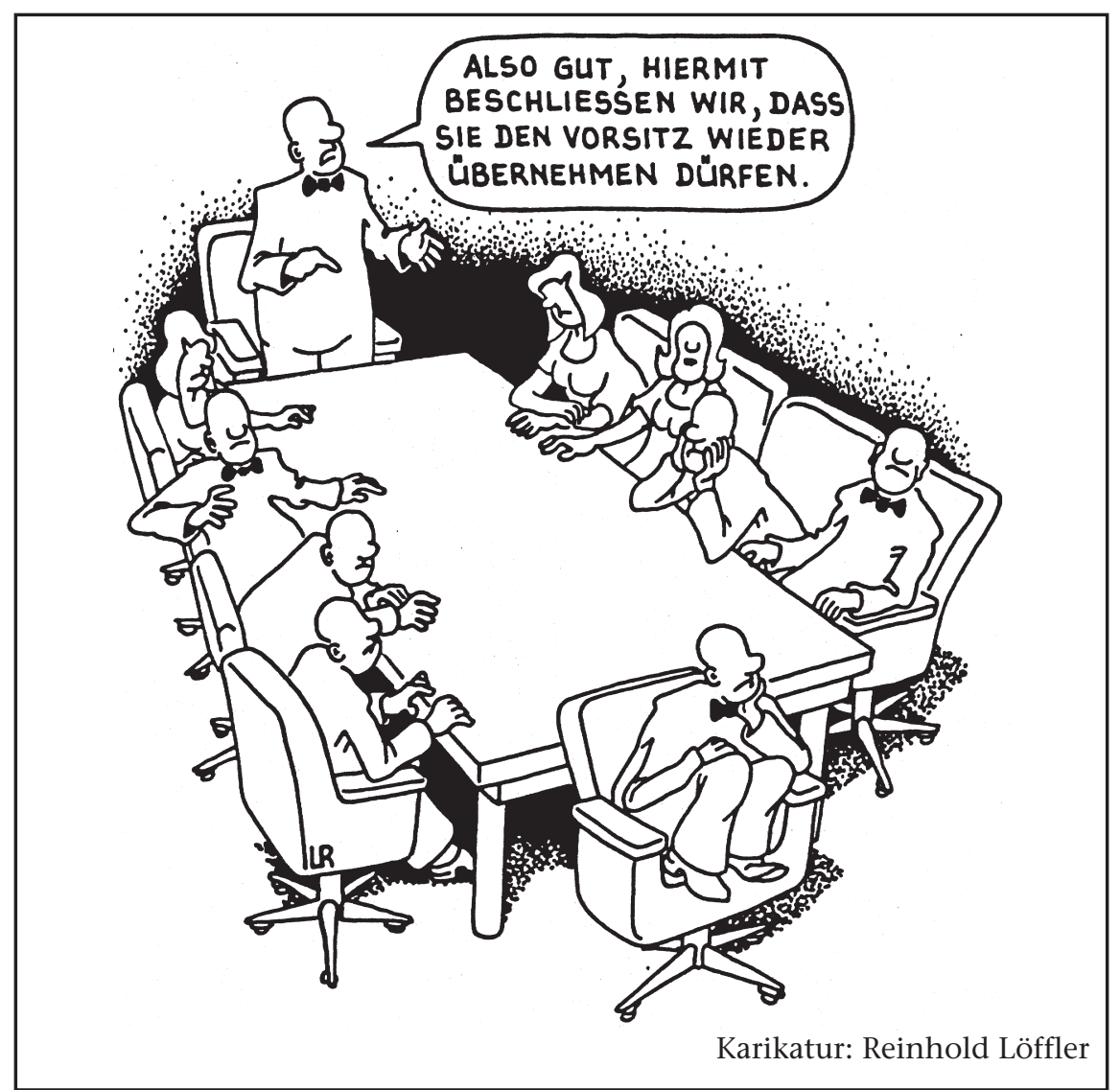

\section{Fragen über Fragen}

»Wieso hat eine 24-Stunden-Einrichtung Schlösser an den Türen? «

"Wie kommt eigentlich das Rasen-betreten-verboten-Schild mitten auf den Rasen? «

»Wenn Schwimmen schlank macht, was machen Blauwale dann falsch? «

»Warum ist nie besetzt, wenn man eine falsche Nummer wählt? «

»Weshalb muss man für den Besuch beim Hellseher einen Termin vereinbaren? «

»Wenn die >Black Box< einen Absturz heil übersteht, warum baut man nicht gleich das ganze Flugzeuge aus diesem Material? «

"Warum glauben einem Leute sofort, wenn man ihnen sagt, dass am Himmel 400 Billionen Sterne stehen, aber wenn man darauf hinweist, dass die Parkbank frisch gestrichen ist, müssen sie draufpatschen? « 